\title{
Non-Vitamin K Antagonist Oral Anticoagulants: New Choices for Patient Management in Atrial Fibrillation
}

\author{
Walid Saliba ${ }^{1}$
}

Published online: 9 June 2015

(c) The Author(s) 2015. This article is published with open access at Springerlink.com

\begin{abstract}
Atrial fibrillation (AF) is a significant problem for the aging population and remains a major factor underlying stroke risk. Warfarin anticoagulation has been proven effective for stroke prevention in AF, but can be difficult to manage and requires frequent monitoring. The non-vitamin $\mathrm{K}$ antagonist oral anticoagulants (NOACs) have been shown to be as effective as warfarin for stroke prevention in nonvalvular $\mathrm{AF}(\mathrm{NVAF})$ and are associated with a reduced risk of bleeding compared with warfarin. Dabigatran, rivaroxaban, apixaban, and edoxaban have been approved in the USA for reducing the risk of stroke in patients with NVAF. In this article, AF risk assessment is discussed and NOAC phase III clinical trials for the prevention of stroke and systemic embolic events are reviewed. Further, differences in stroke and bleeding outcomes between NOACs are highlighted, the use of NOACs for cardioversion and special patient populations is discussed, and management considerations for patients with $\mathrm{AF}$ are reviewed.
\end{abstract}

\section{Key Points}

Non-vitamin K oral anticoagulants (NOACs) are as effective as warfarin for stroke prevention in atrial fibrillation and are associated with less intracranial bleeding.

NOACs may provide a simpler, safer alternative to warfarin.

Walid Saliba

salibaw@ccf.org

1 Cleveland Clinic Main Campus, Mail Code J2-2, 9500 Euclid Avenue, Cleveland, OH 44195, USA

\section{Introduction}

As the US population ages and obesity rates increase, the incidence of atrial fibrillation (AF) is projected to reach 2.6 million cases by 2030 [1]. In the 1991 Framingham study, individuals with AF had a five-times-greater risk of stroke, higher than the risk conveyed by coronary heart disease $(2 \times)$, hypertension $(3 \times)$, or cardiac failure $(4 \times)$ compared with asymptomatic individuals [2]. AF is an independent risk factor for stroke [2] that is present in approximately $10 \%$ of patients aged 50-59 years, increasing to $45 \%$ in those aged $\geq 90$ years [3].

Anticoagulation is recommended for patients with $\mathrm{AF}$ and prior stroke or transient ischemic attack, or for those who are at moderate risk of stroke based on sex, age, vascular disease, diabetes, congestive heart failure, or hypertension [4]. Among patients with AF deemed at moderate to high risk for stroke, anticoagulation is a costeffective treatment for stroke prevention, and may potentially reduce the substantial financial burden associated with stroke due to healthcare costs $[5,6]$; nevertheless, it remains underused [7]. Reasons for this underuse typically include concerns over increased risk of bleeding as well as limitations in healthcare access, facility availability, physician awareness, the inconvenience of monitoring international normalized ratio (INR) levels, and patient compliance $[8,9]$.

Non-vitamin K antagonist (VKA) oral anticoagulants (NOACs) are at least as effective as warfarin for the prevention of stroke in $\mathrm{AF}$ and are associated with significantly decreased risks of intracranial hemorrhage [10]. Dabigatran, rivaroxaban, apixaban, and edoxaban have been approved for reducing the risk of stroke in patients with nonvalvular AF (NVAF) [11-14]. Current guidelines, 
published prior to the approval of edoxaban, recommend dabigatran, rivaroxaban, apixaban, and warfarin for use in NVAF, and further recommend NOACs for patients who are unable to maintain a therapeutic INR on warfarin [4, 15]. Reasons for an inability to maintain a stable INR include patient non-compliance with dietary restrictions, missed doses, and failure to routinely monitor and thus adjust doses when needed, drug-drug interactions, and genetic variability that can affect warfarin metabolism [16]. While using a NOAC will not necessarily improve a patient's compliance with dosing, their pharmacology limits concerns regarding drug-drug and food-drug interactions and the need for routine monitoring [17]. This review discusses current treatment guidelines for $\mathrm{AF}$, provides a brief overview of NOAC pharmacology and the phase III clinical trials for the prevention of stroke and systemic embolic events (SEE), and covers management considerations for patients with AF.

\section{Risk Stratification}

The three main goals in the treatment of AF are rate control, rhythm control, and managing stroke risk. Following confirmation of AF and determination of stroke risk, patients who require anticoagulation should be evaluated to balance the risk of stroke with the risk of bleeding resulting from antithrombotic therapy. Current American Heart Association/American College of Cardiology/Heart Rhythm Society (AHA/ACC/HRS) guidelines recommend risk stratification using the $\mathrm{CHA}_{2} \mathrm{DS}_{2}$-VASc (Congestive heart failure, Hypertension, Age $\geq 75$ years [doubled], Diabetes mellitus, prior Stroke or transient ischemic attack [TIA] or thromboembolism [doubled], Vascular disease, Age 65-74 years, Sex category) scoring system [4, 17] (Fig. 1). $\mathrm{CHA}_{2} \mathrm{DS}_{2}$-VASc outperforms $\mathrm{CHADS}_{2}$ (Congestive heart failure, Hypertension, Age $\geq 75$ years, Diabetes mellitus, prior Stroke or TIA or thromboembolism [doubled]) (Table 1) and the ATRIA (AnTicoagulation and Risk factors In Atrial fibrillation) score in determining patients for whom there is a truly low thrombotic risk [18-20].

Based on this risk stratification, anticoagulation may be omitted for patients who have NVAF and a $\mathrm{CHA}_{2} \mathrm{DS}_{2}$ VASc score of 0 [4]. Oral anticoagulants, aspirin, or no treatment may be considered for patients with an intermediate risk of stroke $\left(\mathrm{CHA}_{2} \mathrm{DS}_{2}-\mathrm{VASc}\right.$ score of 1) [4, 21]. Patients with $\mathrm{NVAF}$ and a $\mathrm{CHA}_{2} \mathrm{DS}_{2}-\mathrm{VASc}$ score $\geq 2$ or who have had a prior stroke or TIA should receive oral anticoagulation, based on current guideline recommendations [4]. Some debate exists regarding the net benefit of anticoagulant treatment in patients with a $\mathrm{CHA}_{2} \mathrm{DS}_{2}$ VASc score of 1. Differing rates of stroke risk in patients with AF and one additional stroke risk have been reported, suggesting that further determination of critical risk factors in various populations should be assessed [20, 22, 23].

Assessment of the 1-year risk of major bleeding in patients with AF by HAS-BLED (Hypertension, Abnormal renal/liver function, Stroke, Bleeding history or predisposition, Labile international normalized ratio, Elderly
Fig. 1 Flowchart of oral anticoagulant use for stroke prevention based on risk factors [4]. ${ }^{a}$ Reduced doses should be considered; safety and efficacy not established. ${ }^{\mathrm{b}}$ Recommended for patients with trouble controlling INR. $\mathrm{CHA}_{2} \mathrm{DS}_{2}-$ $V A S c$ congestive heart failure, hypertension, age $\geq 75$ years (doubled), diabetes mellitus, prior stroke or TIA or thromboembolism (doubled), vascular disease, age 65-74 years, sex category. INR international normalized ratio, $O A C$ oral anticoagulation, TIA transient ischemic attack

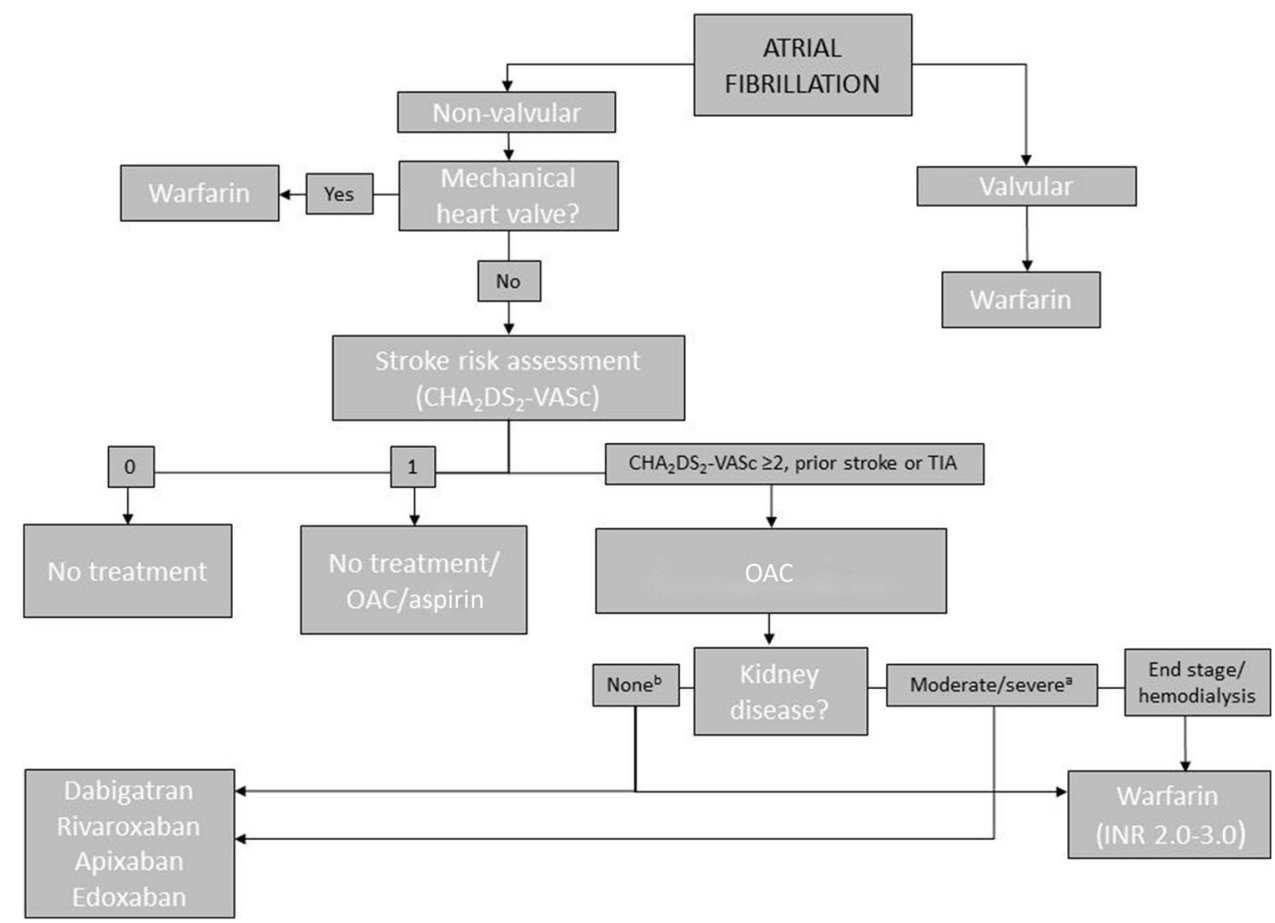


Table 1 Rate of stroke by $\mathrm{CHADS}_{2} / \mathrm{CHADS}_{2}$-VASc score and bleeding risk by HAS-BLED score [4, 24]

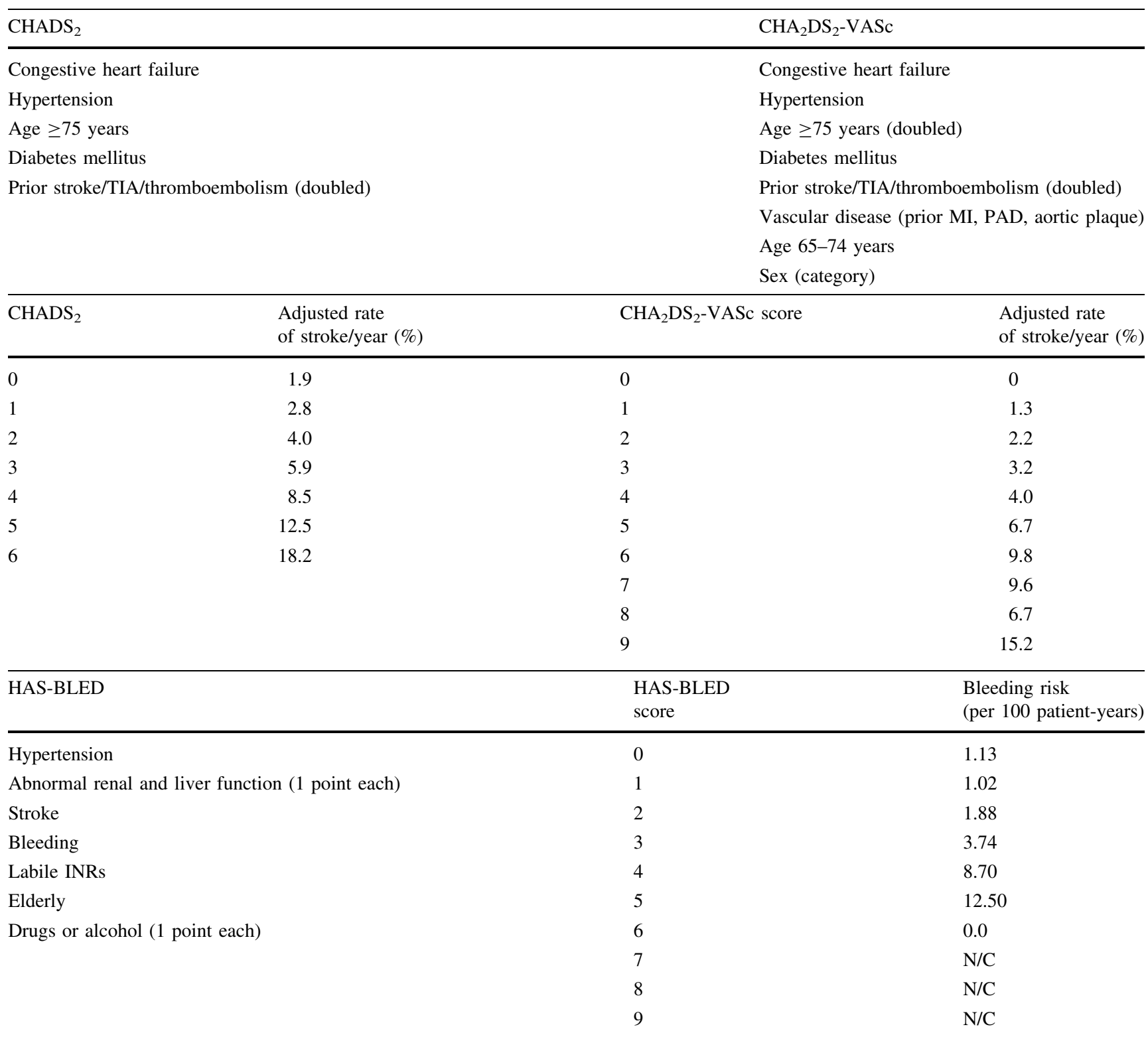

INR international normalized ratio, $M I$ myocardial infarction, $N / C$ not calculated, $P A D$ peripheral arterial disease, $T I A$ transient ischemic attack

[>65 years], Drugs/alcohol concomitantly) [24] is recommended by European Heart Rhythm Association (EHRA), and European Society of Cardiology guidelines, but not AHA/ACC/HRS [4, 25, 26]. To calculate this score, each named clinical characteristic present is assigned 1 point and summed (Table 1) [24]. A HAS-BLED score $\geq 3$ indicates a patient who is potentially at high risk for bleeding events [24]. HAS-BLED demonstrates good predictive accuracy overall, with a better predictive accuracy for patients receiving either no antithrombotic therapy or antiplatelet therapy [24]. In initial validation studies, a score of 1 was associated with a $0.83 \%$ yearly incidence of major bleeding events, whereas a score $>5$ was associated with an incidence of $16.6 \%$ per year [27]. In patients for whom the risk for thromboembolism and bleeding are both high, a comprehensive management approach would include assessment and modification of extrinsic factors that impact risk. These include adequate control of hypertension (both for thromboembolism and bleeding risk), examination of alcohol intake, and the current use of drugs that could increase risk. Furthermore, it should be noted that in patients with AF who develop gastrointestinal (GI) bleeding while receiving warfarin, restarting warfarin is associated with an overall decreased risk of thromboembolism and mortality without a significantly increased risk of recurrent GI bleeding [28]. 


\section{Pharmacology of Non-Vitamin K Antagonist Oral Anticoagulants (NOACs) Versus Warfarin}

Warfarin is relatively inexpensive and readily available, is partially reversible, and has well-understood interactions with other drugs. Warfarin is broadly indicated, and is suitable for patients with mechanical valves [4]. Despite its proven effectiveness, there are several recognized disadvantages of warfarin, including a narrow therapeutic range, drug-drug interactions that can be delayed, food-drug interactions, slow dose-adjustment time, and genetic variability in the enzymes involved in its metabolism, all of which can affect INR [16]. In addition, in order to assure that a therapeutic INR is maintained, frequent patient monitoring is required [4], which some patients may find burdensome. NOACs, which directly inhibit factor Xa (rivaroxaban, apixaban, and edoxaban) or thrombin (dabigatran), were developed to address some of the disadvantages of warfarin. NOACs have a predictable anticoagulant response, making regular laboratory monitoring unnecessary. Anticoagulation with NOACs is achieved quickly, reaching peak plasma concentrations $1-4 \mathrm{~h}$ following oral administration, in comparison with the delayed onset of warfarin (Table 2) [29-32]. Half-lives of NOACs are shorter than that of warfarin, and range from 5 to $15 \mathrm{~h}$ [2932]. NOACs have fewer drug-drug and drug-food interactions than warfarin. Although rivaroxaban should be administered with food [12], the other NOACs can be administered without regard to food.

There are disadvantages associated with NOACs. Bleeding risks increase when NOACs are administered with other anticoagulants, platelet inhibitors, or nonsteroidal anti-inflammatory drugs. NOACs are substrates of the P-glycoprotein (P-gp) transporter [14, 33-36], and many rate-controlling and anti-arrhythmic drugs interact with P-gp [26]. In addition, the NOACs, to varying degrees, are substrates of cytochrome $\mathrm{P} 450$ (CYP) isoenzyme 3A4 [35, 37-39]. As such, co-administration of an NOAC with P-gp inducers or inhibitors and/or CYP3A4 inducers or inhibitors may impact exposure to the NOAC. This is related to the degree to which the NOAC depends on P-gp for transport or on CYP3A4 for metabolism [34, 35]. Thus, verapamil, diltiazem, quinidine, amiodarone, and dronedarone are associated with increased NOAC exposure, and use of these agents may require NOAC dose reduction or may be contraindicated [26] in patients taking NOACs. The lack of laboratory monitoring for NOACs may also be a negative as it is difficult to determine the level of anticoagulation, and compliance can be assessed only by patient feedback and refill frequency $[4,26]$.

\section{Phase III NOAC Clinical Trials}

Phase III clinical trials evaluating NOACs are compared in Table 3. These include the RE-LY (Randomized Evaluation of Long-Term Anticoagulation Therapy) [40], ROCKET AF (Rivaroxaban Once Daily Oral Direct Factor Xa Inhibition Compared with Vitamin K Antagonism for Prevention of Stroke and Embolism Trial in Atrial Fibrillation) [41], ARISTOTLE (Apixaban for Reduction in Stroke and Other Thromboembolic Events in Atrial Fibrillation) [42], and the ENGAGE AF-TIMI 48 trial (Effective Anticoagulation with Factor Xa Next Generation in Atrial Fibrillation-Thrombolysis in Myocardial Infarction Study 48) [43]. All of these trials included both hemorrhagic and ischemic events in the primary efficacy endpoint of stroke and SEE (Table 3).

Table 2 Non-vitamin K antagonist anti-coagulant pharmacology [11, 12, 34, 39, 44, 45]

\begin{tabular}{|c|c|c|c|c|}
\hline & Dabigatran & Rivaroxaban & Apixaban & Edoxaban \\
\hline $\begin{array}{l}\text { Time to maximal } \\
\text { concentration }(\mathrm{h})\end{array}$ & $1-3$ & $2-4$ & $3-4$ & $1-2$ \\
\hline Half-life (h) & $12-17$ & $5-9$ & 12 & $10-14$ \\
\hline $\begin{array}{l}\text { Renal elimination }{ }^{\mathrm{a}} \\
(\%)\end{array}$ & 80 & 66 & 27 & 35 \\
\hline Transporters & P-gp & P-gp/BCRP & P-gp/BCRP & P-gp \\
\hline $\begin{array}{l}\text { Metabolized by } \\
\text { CYP450 }\end{array}$ & No relevant effect & Yes & Yes & No relevant effect \\
\hline $\begin{array}{c}\text { Potential drug } \\
\text { interactions }\end{array}$ & $\begin{array}{l}\text { P-gp inhibitors in the } \\
\text { background of renal } \\
\text { impairment and P-gp } \\
\text { inducers }\end{array}$ & $\begin{array}{l}\text { Combined P-gp and } \\
\text { strong CYP3A4 } \\
\text { inhibitors and inducers }\end{array}$ & $\begin{array}{l}\text { Strong dual inhibitors of } \\
\text { CYP3A4 and P-gp increase } \\
\text { blood levels; strong dual } \\
\text { inducers of CYP3A4 and P-gp }\end{array}$ & $\begin{array}{l}\text { Potent inhibitors } \\
\text { of P-gp }\end{array}$ \\
\hline
\end{tabular}

$B C R P$ breast cancer resistance protein, $C Y P 3 A 4$ cytochrome $\mathrm{P} 450$ isoform $3 \mathrm{~A} 4, P$-gp $\mathrm{P}$-glycoprotein

${ }^{a}$ For dabigatran, based on absorbed dose; for rivaroxaban, apixaban, and edoxaban, based on orally administered dose 
Table 3 Key aspects of the non-vitamin K antagonist anti-coagulant phase III clinical trials [40-43]

\begin{tabular}{|c|c|c|c|c|c|c|}
\hline Trial & Dosing & Design & $\begin{array}{l}\text { Patients } \\
\text { enrolled } \\
(n)\end{array}$ & $\begin{array}{l}\text { Mean } \\
\text { CHADS }_{2} \\
\text { score }^{\mathrm{a}}\end{array}$ & $\begin{array}{l}\text { Median } \\
\text { follow-up } \\
\text { (years) }\end{array}$ & $\begin{array}{l}\text { Mean } \\
\text { percent } \\
\text { TTR }\end{array}$ \\
\hline \multicolumn{7}{|l|}{ RE-LY } \\
\hline $\begin{array}{l}\text { Dabigatran } \\
\text { Warfarin }\end{array}$ & $\begin{array}{l}110 \text { or } 150 \mathrm{mg} \text {, bid } \\
\text { Dose adjusted to INR } 2.0-3.0\end{array}$ & $\begin{array}{l}\text { Non-inferiority, prospective, } \\
\text { randomized, open-label for } \\
\text { warfarin, blinded for } \\
\text { dabigatran }\end{array}$ & 18,113 & 2.1 & 2.0 & 64 \\
\hline \multicolumn{7}{|l|}{ ROCKET AF } \\
\hline $\begin{array}{l}\text { Rivaroxaban } \\
\text { Warfarin }\end{array}$ & $\begin{array}{l}20 \mathrm{mg} \text { od, } 15 \mathrm{mg} \text { daily } \\
\text { in pts with } \mathrm{Cl}_{\mathrm{Cr}} 30-49 \mathrm{ml} / \mathrm{min} \\
\text { Dose adjusted to INR } 2.0-3.0\end{array}$ & $\begin{array}{l}\text { Non-inferiority, prospective, } \\
\text { randomized double-blind, } \\
\text { double-dummy, parallel-arm }\end{array}$ & 14,264 & 3.5 & 1.9 & 55 \\
\hline \multicolumn{7}{|l|}{ ARISTOTLE } \\
\hline Apixaban & $\begin{array}{l}5 \mathrm{mg} \text { bid; } 2.5 \mathrm{mg} \text { bid in pts with } \geq 2 \text { of the } \\
\text { following: age } \geq 80 \text { years, body } \\
\text { weight } \leq 60 \mathrm{~kg} \text {, or serum creatinine } \\
\geq 1.5 \mathrm{mg} / \mathrm{dl}(133 \mu \mathrm{mol} / \mathrm{l})\end{array}$ & $\begin{array}{l}\text { Non-inferiority, prospective, } \\
\text { randomized double-blind, } \\
\text { double-dummy, parallel-arm }\end{array}$ & 18,201 & 2.1 & 1.8 & 62 \\
\hline Warfarin & Dose adjusted to INR $2.0-3.0$ & & & & & \\
\hline \multicolumn{7}{|l|}{ ENGAGE AF } \\
\hline Edoxaban & $\begin{array}{l}60 \text { or } 30 \mathrm{mg} \text { od; } 50 \% \text { dose reduction for pts with } \\
\text { a Cl} \mathrm{Cr} 30-50 \mathrm{ml} / \mathrm{min} \text {, body weight } \leq 60 \mathrm{~kg} \text {, or } \\
\text { concomitant treatment with P-gp inhibitors }\end{array}$ & $\begin{array}{l}\text { Non-inferiority, prospective, } \\
\text { randomized double-blind, } \\
\text { double-dummy, parallel-arm }\end{array}$ & 21,105 & 2.8 & 2.8 & 65 \\
\hline Warfarin & Dose adjusted to INR $2.0-3.0$ & & & & & \\
\hline
\end{tabular}

bid twice daily, $C I$ confidence interval, $C l_{C r}$ creatinine clearance, $C R N M$ clinically relevant non-major, INR international normalized ratio, od once daily, $P$ - $g p$ P-glycoprotein, $p t s$ patients, TTR time in therapeutic range

${ }^{a}$ In ROCKET AF, INRs calculated 7 days after randomization and during treatment interruptions were excluded from calculation

The NOAC clinical trials cannot be directly compared due to differences in study design and enrolled populations. Notably, RE-LY was a prospective, randomized, openblinded, endpoint trial, and the other three trials employed a double-blind, double-dummy design. (Table 3). Additionally, the number of tested doses, dose frequency, and patient criteria for their administration differed among the four trials. RE-LY evaluated two doses of dabigatran twice daily, ROCKET AF evaluated one daily dose of rivaroxaban, ARISTOTLE evaluated one twice-daily dose of apixaban, and ENGAGE AF evaluated two once-daily doses of edoxaban, with dose reductions, as described above, allowed in ROCKET AF, ARISTOTLE, and ENGAGE AF [40-43]. RE-LY and ARISTOTLE assessed non-inferiority and superiority in the intention-to-treat population, ROCKET AF assessed non-inferiority in patients who were protocol-compliant on treatment and superiority in the on-treatment and intention-to-treat population, ENGAGE AF assessed non-inferiority in the modified intention-to-treat population, comprising patients who underwent randomization and received at least one dose of study drug, and superiority in the intention-to-treat population [40-43].
Each of the trials required a diagnosis of AF for inclusion in the study, with the exception of ARISTOTLE, which included both AF and atrial flutter [42]. Larger proportions of patients with paroxysmal AF were enrolled in RE-LY (33 \%) and ENGAGE AF (25\%) compared with ROCKET AF (18\%) and ARISTOTLE (15\%). Due to differences in $\mathrm{CHADS}_{2}$ score inclusion criteria, patients with higher mean $\mathrm{CHADS}_{2}$ scores were enrolled in ROCKET AF (3.5) and ENGAGE AF (2.8) compared with RE-LY and ARISTOLE (2.1 for both) (Table 4) [40-43].

\section{Differences in the NOAC Phase III Trial Outcomes}

\subsection{Rates of Stroke, Systemic Embolism, and Myocardial Infarction}

Overall, the results of the phase III trials indicate that the ability of NOACs to prevent strokes and SEEs is comparable or better than that of warfarin (Table 4). It is important to note that the percent time in therapeutic range (TTR) on warfarin differed between the trials, but was 


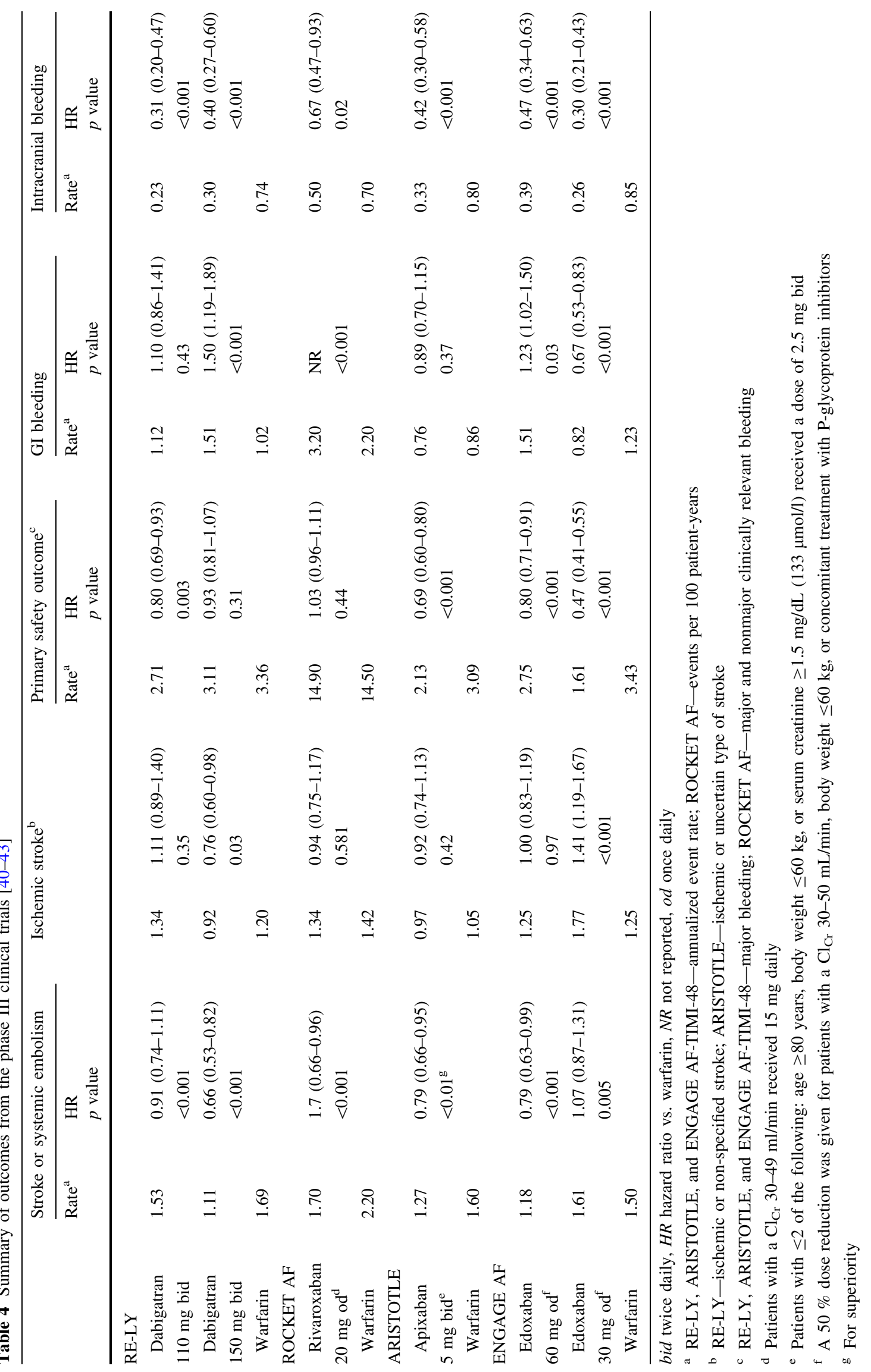


higher than a reported mean US-based "real-world" TTR of $53.7 \%$ [46], for all clinical trials with the exception of ROCKET, and the highest mean TTR was achieved in the ENGAGE AF trial (Table 3). Rates of ischemic stroke were similar in trials for rivaroxaban and apixaban relative to warfarin; dabigatran $150 \mathrm{mg}$ was associated with a lower rate of ischemic stroke relative to warfarin, although the $110-\mathrm{mg}$ dose resulted in a similar rate relative to warfarin [40-42]. Rates of ischemic stroke were similar to those for warfarin for the high-dose edoxaban regimen, but more frequent with the low-dose edoxaban regimen [43]. Each NOAC provided significantly greater reductions in the risk for intracranial bleeding compared with warfarin.

In ROCKET AF, patients with a history of myocardial infarction (MI) tended to have worse cardiovascular and bleeding outcomes than patients without a history of MI [47]. Rates of intracranial hemorrhage (ICH) and fatal bleeding associated with rivaroxaban use were lower compared with warfarin in both patients with and without a history of prior MI [47]. Rates of MI were not significantly different between patients treated with apixaban and warfarin [42] or in patients treated with edoxaban compared with warfarin [43]. Although rates of MI were initially reported as significantly increased by dabigatran [40], this trend has not persisted in later analyses, in which the MI rate was similar to that with warfarin [48].

\subsection{Bleeding Rates}

Overall, the results of the phase III trials indicate that rates of major bleeding or major bleeding and clinically relevant non-major (CRNM) bleeding with NOACs are comparable or better than with warfarin (Table 4). Rates of major bleeding were similar between dabigatran $150 \mathrm{mg}$ and warfarin, although rates of major bleeding were significantly reduced with dabigatran $110 \mathrm{mg}$ [40]. Likewise, rates of the composite of major bleeding and CRNM bleeding were similar between rivaroxaban and warfarin [41]. Rates of major bleeding were significantly reduced relative to warfarin for apixaban and both dosing regimens of edoxaban [42, 43].

Approximately $10 \%$ of all cases of ICH occur in patients receiving warfarin [49]. Warfarin is associated with a reduced risk of thromboembolism compared with no therapy, and a $31 \%$ reduction in all-cause mortality, but increases the risk of ICH twofold [50]. The NOACs perform significantly better than warfarin in reducing intracranial bleeding risks. In each NOAC phase III trial, intracranial bleeding rates were significantly decreased relative to warfarin for all drugs and doses [40-43] (Table 4). Compared with warfarin, apixaban reduces the risk of a first major hemorrhage by $31 \%$ and is associated with fewer ICHs, fewer trauma-associated hemorrhages, and a $50 \%$ reduction in major hemorrhage leading to death within 30 days of the event [51]. In a subanalysis of RE-LY, 154 ICHs occurred in 153 patients, with an overall 30-day mortality rate of $36 \%$. Patients who suffered an ICH tended to be older, with a history of stroke or TIA, more likely to have taken aspirin, less likely to have heart failure, and more likely to have a lower estimated creatinine clearance $\left(\mathrm{Cl}_{\mathrm{Cr}}\right)$ [52]. Lower rates of $\mathrm{ICH}$, fatal $\mathrm{ICH}$, and subdural hematoma were noted in the patients receiving dabigatran compared with warfarin [52]. Both the higherand lower-dose once-daily edoxaban regimens are associated with significant reductions in various subtypes of intracranial bleeding compared with warfarin [53]. Fewer numbers of ICHs are projected to result in fewer clinical events, reduced stroke severity, and lower treatment and follow-up-related costs for patients treated with NOACs [54].

In general, the NOACs are associated with an increased risk for GI bleeding; however, the risk varies across drugs [10]. Dabigatran $150 \mathrm{mg}$ is associated with higher rates of GI bleeding than warfarin, whereas GI bleeding rates for dabigatran $110 \mathrm{mg}$ do not significantly differ from warfarin [40]. This latter dose has not been approved in the USA, but has been approved for use in Canada and the EU [55, 56]. Although there have been many postmarketing reports of serious and fatal bleeding events associated with dabigatran, bleeding rates associated with dabigatran do not appear to be higher than those associated with warfarin based on an analysis of insurance-claim data and administrative data from the US FDA Mini-Sentinel Database [57]. However, other analyses confirm greater rates of GI bleeding associated with dabigatran [58]. GI bleeding rates are increased for rivaroxaban compared with warfarin [41]. Apixaban has not been shown to have significantly different GI bleeding rates compared with warfarin [42]. High-dose edoxaban results in more frequent GI bleeds than warfarin; however, low-dose edoxaban results in fewer GI bleeds relative to warfarin (Table 4) [10].

\section{Additional Analyses}

\subsection{Clopidogrel/Aspirin}

In AVERROES (Apixaban vs. Acetylsalicylic Acid to Prevent Stroke in Atrial Fibrillation Patients who have Failed or are Unsuitable for Vitamin K Antagonist Treatment), apixaban was superior to aspirin for stroke prevention and carried a similar bleeding risk. Roughly 1 year after treatment, fewer patients who received apixaban than patients who received aspirin were hospitalized for cardiovascular reasons [59]. This reduction was driven primarily by fewer stroke-related hospitalizations. 
In a subanalysis of RE-LY examining concomitant antiplatelet use and dabigatran or warfarin use, the risks of major bleeding were higher for patients receiving dual antiplatelet therapy than only a single antiplatelet medication [60]. The efficacy and safety of dabigatran was similar for patients receiving antiplatelet therapy with dabigatran compared with patients receiving dabigatran only. However, this subanalysis was not statistically powered for comparisons, and more studies of these interactions would be beneficial. The efficacy and safety of apixaban was not different between patients with or without concomitant aspirin use in the ARISTOTLE trial [61]. In a subanalysis of ENGAGE AF, both low- and high-dose edoxaban regimens had similar efficacy but significantly reduced major bleeding compared with warfarin in patients receiving concomitant antiplatelet medication [62].

\subsection{NOACs and Cardioversion/Ablation}

Thromboembolic risk around the time of cardioversion can be reduced by appropriate anticoagulation management [4]. As warfarin has a delayed onset of action, patients may require bridging therapy with heparin or low-molecularweight heparin (LMWH) if a therapeutic INR range is not achieved or if a patient is new to VKA. On the other hand, due to their rapid onset, the use of NOACs may potentially be advantageous for this procedure.

Most studies examining cardioversion and NOAC use have been small and generally have not been sufficiently powered for statistical analysis. Patients undergoing electrical cardioversion, pharmacologic cardioversion, or catheter ablation who received continuous rivaroxaban treatment had similar numbers of incidents of stroke or systemic embolism and similar rates of major or CRNM bleeding compared with patients treated with warfarin during cardioversion [63]. In a prospective, randomized clinical trial of patients undergoing cardioversion, similar rates of the composite of stroke, TIA, peripheral embolism, MI, and cardiovascular death and major bleeding were associated with rivaroxaban and warfarin, as well as similar rates of major bleeding [64]. Rivaroxaban was also associated with a significantly shorter time to cardioversion than was warfarin [64]. Clinical events occurring after cardioversion for AF were comparable in patients who had received apixaban and warfarin at randomization; event rates were small and did not differ for patients receiving continuous administration of study drug [65]. Among patients undergoing cardioversion receiving dabigatran $110 \mathrm{mg}$, dabigatran $150 \mathrm{mg}$, or warfarin, rates of stroke and SEE within 30 days of the procedure were low [66]. Some studies have shown increases in thromboembolic complications including stroke and TIA following peri- procedural use of dabigatran for AF ablation, yet other studies have not shown any increase in risk $[67,68]$. Additional studies on the use of NOACs for cardioversion and ablation are ongoing.

\subsection{Atrial Fibrillation and Transient Ischemic Attack/Heart Failure}

Only a few subanalyses have examined the use of NOACs for stroke prevention in AF patients with heart failure or prior TIA. Apixaban had efficacy and safety superior to that of warfarin for patients with AF and left ventricular systolic dysfunction and heart failure-preserved ejection fraction, with the greatest absolute benefits in the highest risk patients with left ventricular systolic dysfunction [69]. No differences in treatment-related outcomes were shown between patients with previous stroke or TIA for dabigatran compared with warfarin, with the exception of vascular death [70]. Dabigatran, rivaroxaban, and edoxaban have shown consistent effects relative to warfarin for patients with heart failure compared with patients without heart failure [71, 72].

\section{Patient Management}

Transitions between NOACs should be managed in accordance with label instructions, individual patient characteristics, and the half-life and speed of onset of each NOAC [73]. When transitioning from a NOAC to warfarin, treatment with warfarin should be overlapped with the NOAC to allow effective levels of anticoagulation to be reached [25], with INR monitored until a stable level of 2-3 has been achieved [26]. Initiation of warfarin treatment requires daily checks until a therapeutic range of 2.0-3.0 has been reached and sustained for 2 consecutive days. When switching from warfarin to an NOAC, the INR should be adjusted to an INR $<2$ for patients who will receive dabigatran or apixaban, $\leq 2.5$ for patients who will receive edoxaban, or $<3$ for patients who will receive rivaroxaban prior to NOAC administration, to prevent excessive anticoagulation [11-14].

Boxed warnings have been issued for dabigatran, apixaban, edoxaban, and rivaroxaban due to an increased risk of thromboembolic events following treatment discontinuation [11-14]. Continued anticoagulation is recommended for these patients unless pathological bleeding prompted discontinuation; coverage with another anticoagulant should be provided if patients discontinue for reasons other than pathological bleeding [11-14].

Since the NOACs have short half-lives, it is important that patients are properly educated regarding their use, as 
missing a dose could negatively affect anticoagulation. Cessation of anticoagulant therapy has been associated with high rates of stroke, SEE, and all thrombotic events [74]. These concerns highlight the importance of education for all patients taking anticoagulants.

\subsection{Peri-Procedural Management}

Recommendations call for discontinuation of warfarin therapy 5 days prior to surgery for elective procedures [75]. Patients with $\mathrm{AF}$ at a high risk of thromboembolism should be given bridging therapy with heparin [75]. The majority of interventions do not require bridging with LMWH $[4,26]$. NOACs can be discontinued 24 and $48 \mathrm{~h}$ before procedures associated with risk of minor and major bleeding, respectively $[4,26]$. Apixaban or rivaroxaban should be discontinued $36 \mathrm{~h}$ prior to low-risk procedures for patients with kidney dysfunction $\left(\mathrm{Cl}_{\mathrm{Cr}} 15-30 \mathrm{ml} / \mathrm{min}\right)$ [26]. The time necessary for dabigatran discontinuation prior to procedures is graded by renal function, with longer times recommended prior to procedures for patients with greater degrees of renal impairment [26]. Therapy with NOACs can be reinitiated following surgery once effective hemostasis is achieved. Interventions to stabilize patients who are hemodynamically unstable and require emergency cardioversion should not be delayed due to initiation of anticoagulation [4].

\subsection{Management of Bleeding}

No quantitative tests of anticoagulation exist for the NOACs; however, qualitative levels of NOAC anticoagulation can be assessed if the time of last dose of anticoagulant is known. The decision to discontinue or reverse anticoagulation should be made in consideration of the time sensitivity of the clinical situation [73]. Reversal of warfarin can be achieved with administration of vitamin K, fresh frozen plasma, or coagulation factors [76]. Currently, the NOACs lack specific reversal agents. Prothrombin complex concentrate (PCC) infusion reverts thrombin generation-endogenous thrombin potential to near baseline values and reverses rivaroxaban-induced increased prothrombin time [77, 78]. PCC infusion also reverses the effects of edoxaban on endogenous thrombin potential, but not prothrombin time $[79,80]$. The use of activated PCC, factor VIII inhibitor bypassing activity, and an active recombinant form of factor VII [78, 81, 82] have also been assessed as reversal agents; however, these drugs were developed as hemostatic agents for bleeding and bleeding deficiencies, not for reversal of direct FXa or IIa inhibition [83, 84]. The synthetic small-molecule PER977 [85, 86], catalytically inactive human recombinant FXa andexanet alfa (PRT064445) [87], and an antibody fragment specific to dabigatran [88] are also under investigation as specific reversal agents.

A total of $87-95 \%$ of rivaroxaban and apixaban bind plasma proteins, $35 \%$ of dabigatran, and $40-59 \%$ of edoxaban is protein bound $[12,14,31,89]$. The low protein binding of dabigatran allows it to be removed by dialysis, as recommended by the package insert, although this may not be feasible in unstable patients. Dialysis is not effective for removal of rivaroxaban [12] edoxaban [13], or apixaban [14].

\subsection{Specific Populations}

\subsubsection{Renal Impairment}

Consideration of renal function is important prior to initiation of NOAC treatment. Although the renal clearance of NOACs vary, patients with renal impairment may require dose reduction to avoid increased plasma concentrations of NOACs [4, 90-92]. Of the NOACs, dabigatran is the most dependent on renal function, with $>80 \%$ of the dabigatran dose that is absorbed excreted in urine [37]. Rivaroxaban, edoxaban, and apixaban have less renal dependence, and are excreted via urine by 66,50 , and $27 \%$, respectively [12-14]. AF patients with mild or moderate renal impairment $\left(\mathrm{Cl}_{\mathrm{Cr}} 30-49 \mathrm{ml} / \mathrm{min}\right)$ may receive dabigatran $150 \mathrm{mg}$ twice daily [11]. A reduced dose of $75 \mathrm{mg}$ twice daily is recommended for patients with a $\mathrm{Cl}_{\mathrm{Cr}}$ 15-30 ml/min [11]; however, these patients were not included in the randomized clinical trial. Rivaroxaban is not recommended in patients with a $\mathrm{Cl}_{\mathrm{Cr}}<15 \mathrm{ml} / \mathrm{min}$, and renal function should be monitored in all patients receiving the drug. Patients who have any two of age $\geq 80$ years, body weight $\leq 60 \mathrm{~kg}$, or elevated serum creatinine $(\geq 1.5 \mathrm{mg} / \mathrm{dl})$ should receive an adjusted dose of apixaban $2.5 \mathrm{mg}$ twice daily [14]. Edoxaban doses should be reduced to $30 \mathrm{mg}$ once daily in patients with a $\mathrm{Cl}_{\mathrm{Cr}}$ $15-50 \mathrm{ml} / \mathrm{min}$ [13]. Edoxaban should not be used in patients with a $\mathrm{Cl}_{\mathrm{Cr}}>95 \mathrm{ml} / \mathrm{min}$ [13].

Generally, bleeding rates with NOACs are similar or reduced relative to warfarin in patients with renal impairment. Major bleeding rates for dabigatran 110 and $150 \mathrm{mg}$ were similar to warfarin in this patient group [93]. Patients with $\mathrm{Cl}_{\mathrm{Cr}} \leq 50 \mathrm{ml} / \mathrm{min}$ receiving apixaban had more significant reductions in major bleeding than those with higher $\mathrm{Cl}_{\mathrm{Cr}}$, even after adjusting for patients who received a reduced dose of $2.5 \mathrm{mg}$ twice daily [94]. Less critical organ bleeding and fatal bleeding occurred with rivaroxaban $15 \mathrm{mg}$ compared with warfarin in patients with $\mathrm{Cl}_{\mathrm{Cr}}$ 30-49 $\mathrm{ml} / \mathrm{min}[95,96]$. In a prespecified post hoc analysis of ENGAGE AF, patients with a $\mathrm{Cl}_{\mathrm{Cr}} 30-50 \mathrm{ml} / \mathrm{min}$ experienced fewer adjudicated major bleeding events compared with warfarin [13]. 


\subsubsection{Aged Patients}

Hemorrhage risk increases with prior stroke and GI bleeding, hypertension, concomitant use of antiplatelet medication, anemia, renal insufficiency, the presence of cerebrovascular disease, and malignancy, all of which may be more common in the elderly [97]. Further, elderly patients are more likely to take multiple medications and may not receive sufficient patient education. However, advanced age should not be seen as a contraindication to oral anticoagulant treatment [98]. Warfarin significantly reduces stroke risk in the elderly, and reduces the risk of ischemic stroke compared with aspirin [97]; however, the risk of major hemorrhage increases with age [99].

In general, the NOACs demonstrated similar efficacy and safety in patients aged $\geq 75$ compared with those aged $<75$ years [10]. Rates of stroke or SEE are reduced relative to warfarin and are associated with a lower risk of bleeding in phase III trials [41-43]. Older age also had no impact on the efficacy or safety of edoxaban, rivaroxaban, or apixaban compared with younger patients [41-43]. Rates of stroke for patients aged $\geq 75$ years compared with younger patients were not reported for dabigatran; however, dabigatran showed a significant interaction of age by treatment, with both dabigatran $110 \mathrm{mg}$ and dabigatran $150 \mathrm{mg}$ producing a higher risk of major bleeding in patients aged $\geq 75$ years compared with those aged $<75$ years [100]. Compared with warfarin, edoxaban decreased the absolute risk of major bleeding, including ICH, in elderly patients [101].

\subsection{Dosing Recommendations with Certain Concomitant Medications}

Both rivaroxaban and apixaban are metabolized via CYP3A4 [12, 14]. Dabigatran is not a CYP3A4 substrate [37], and the metabolites of edoxaban generated by CYP3A4 activity account for $<5 \%$ of edoxaban exposure [13]. Due to these considerations, apixaban should be given at a reduced dose or concomitant use should be avoided in patients who are also taking strong P-gp and CYP3A4 inhibitors [14]. Dabigatran should be given at a reduced dose to patients with moderate renal impairment who are taking P-gp inhibitors [11], and rivaroxaban should not be administered to patients taking combined P-gp and strong inducers and inhibitors of CYP3A4 [12]. No edoxaban dose reductions are required for concomitant P-gp inhibitor use or CYP3A4 in patients with NVAF [13]. The concomitant use of edoxaban with rifampin, a strong P-gp inducer, should be avoided [13].

\section{Conclusions}

In clinical trials, NOACs have demonstrated comparable or better risk reductions for stroke and SEE and for bleeding compared with warfarin. In particular, they all significantly reduce the risk for $\mathrm{ICH}$. Patients treated with NOACs are projected to have fewer clinical events and reduced stroke severity, primarily due to fewer numbers of ICHs. Further, the use of NOACs provides more options for specific patient groups, depending on their characteristics and concomitant medications. The risk of GI bleeding should be taken under consideration for patients receiving NOACs; however, some patient populations may benefit greatly from the use of NOACs over traditional warfarin therapy.

Acknowledgments The author would like to acknowledge writing assistance provided by Terri Schochet, $\mathrm{PhD}$, of AlphaBioCom, LLC, which was funded by Daiichi Sankyo, Inc.

Conflict of interest The author declares no conflicts of interest.

Open Access This article is distributed under the terms of the Creative Commons Attribution-NonCommercial 4.0 International License (http://creativecommons.org/licenses/by-nc/4.0/), which permits any noncommercial use, distribution, and reproduction in any medium, provided you give appropriate credit to the original author(s) and the source, provide a link to the Creative Commons license, and indicate if changes were made.

\section{References}

1. Colilla S, Crow A, Petkun W, Singer DE, Simon T, Liu X. Estimates of current and future incidence and prevalence of atrial fibrillation in the U.S. adult population. Am J Cardiol. 2013;112(8):1142-7.

2. Wolf PA, Abbott RD, Kannel WB. Atrial fibrillation as an independent risk factor for stroke: the Framingham Study. Stroke. 1991;22(8):983-8.

3. Marini C, De Santis F, Sacco S, et al. Contribution of atrial fibrillation to incidence and outcome of ischemic stroke: results from a population-based study. Stroke. 2005;36(6):1115-9.

4. January CT, Wann LS, Alpert JS, et al. 2014 AHA/ACC/HRS Guideline for the Management of Patients With Atrial Fibrillation: a Report of the American College of Cardiology/American Heart Association Task Force on Practice Guidelines and the Heart Rhythm Society. J Am Coll Cardiol. 2014;64(21):e1-76.

5. Harrington AR, Armstrong EP, Nolan PE Jr, Malone DC. Costeffectiveness of apixaban, dabigatran, rivaroxaban, and warfarin for stroke prevention in atrial fibrillation. Stroke. 2013;44(6):1676-81.

6. Hughes M, Lip GY, Guideline Development Group for the NICE National Clinical Guideline for Management of Atrial Fibrillation in Primary and Secondary Care. Stroke and thromboembolism in atrial fibrillation: a systematic review of stroke risk factors, risk stratification schema and cost effectiveness data. Thromb Haemost. 2008;99(2):295-304.

7. Ogilvie IM, Newton N, Welner SA, Cowell W, Lip GY. Underuse of oral anticoagulants in atrial fibrillation: a systematic review. Am J Med. 2010;123(7):638-645 e4. 
8. Bungard TJ, Ghali WA, Teo KK, McAlister FA, Tsuyuki RT. Why do patients with atrial fibrillation not receive warfarin? Arch Intern Med. 2000;160(1):41-6.

9. Hess PL, Mirro MJ, Diener HC, et al. Addressing barriers to optimal oral anticoagulation use and persistence among patients with atrial fibrillation: proceedings, Washington, DC, December 3-4, 2012. Am Heart J. 2014;168(3):239-47 e1.

10. Ruff CT, Giugliano RP, Braunwald E, et al. Comparison of the efficacy and safety of new oral anticoagulants with warfarin in patients with atrial fibrillation: a meta-analysis of randomised trials. Lancet. 2014;383(9921):955-62.

11. PRADAXA ${ }^{\circledR}$ (dabigatran etexilate mesylate) Full Prescribing Information. Ridgefield: Boehringer Ingelheim Pharmaceuticals, Inc; 2014.

12. XARELTO ${ }^{\circledR}$ (rivaroxaban) tablets. Full prescribing information. Titusville: Janssen Pharmaceuticals; 2014.

13. SAVAYSA ${ }^{\mathrm{TM}}$ (edoxaban) tablets for oral use Full Prescribing Information. Parsippany: Daiichi Sankyo Inc; 2015.

14. Eliquis (Apixaban) tablets for oral use. Full Prescribing Information. Princeton and Pfizer Inc, New York: Bristol-Myers Squibb Company; 2014.

15. European Heart Rhythm Association, European Association for Cardio-Thoracic Surgery, Camm AJ, et al. Guidelines for the management of atrial fibrillation: the Task Force for the Management of Atrial Fibrillation of the European Society of Cardiology (ESC). Eur Heart J. 2010;31(19):2369-429.

16. Hirsh J, Fuster V, Ansell J, Halperin JL, American Heart Association/American College of Cardiology F. American Heart Association/American College of Cardiology Foundation guide to warfarin therapy. J Am Coll Cardiol. 2003;41(9):1633-52.

17. Lip GY, Nieuwlaat R, Pisters R, Lane DA, Crijns HJ. Refining clinical risk stratification for predicting stroke and thromboembolism in atrial fibrillation using a novel risk factor-based approach: the euro heart survey on atrial fibrillation. Chest. 2010;137(2):263-72.

18. Potpara TS, Polovina MM, Licina MM, Marinkovic JM, Prostran MS, Lip GY. Reliable identification of "truly low" thromboembolic risk in patients initially diagnosed with "lone" atrial fibrillation: the Belgrade atrial fibrillation study. Circ Arrhythm Electrophysiol. 2012;5(2):319-26.

19. Lip GY, Nielsen PB, Skjoth F, Lane DA, Rasmussen LH, Larsen TB. The value of the European society of cardiology guidelines for refining stroke risk stratification in patients with atrial fibrillation categorized as low risk using the anticoagulation and risk factors in atrial fibrillation stroke score: a nationwide cohort study. Chest. 2014;146(5):1337-46.

20. Olesen JB, Lip GY, Hansen ML, et al. Validation of risk stratification schemes for predicting stroke and thromboembolism in patients with atrial fibrillation: nationwide cohort study. BMJ. 2011;342:d124.

21. Lip GY, Frison L, Halperin JL, Lane DA. Identifying patients at high risk for stroke despite anticoagulation: a comparison of contemporary stroke risk stratification schemes in an anticoagulated atrial fibrillation cohort. Stroke. 2010;41(12):2731-8.

22. Chao TF, Liu CJ, Wang KL, et al. Should atrial fibrillation patients with 1 additional risk factor of the CHA2DS2-VASc score (beyond sex) receive oral anticoagulation? J Am Coll Cardiol. 2015;65(7):635-42.

23. Friberg L, Skeppholm M, Terent A. Benefit of anticoagulation unlikely in patients with atrial fibrillation and a $\mathrm{CHA}_{2} \mathrm{DS}_{2^{-}}$ VASc score of 1. J Am Coll Cardiol. 2015;65(3):225-32.

24. Pisters R, Lane DA, Nieuwlaat R, de Vos CB, Crijns HJ, Lip GY. A novel user-friendly score (HAS-BLED) to assess 1-year risk of major bleeding in patients with atrial fibrillation: the Euro Heart Survey. Chest. 2010;138(5):1093-100.
25. Camm AJ, Lip GY, De Caterina R, et al. 2012 focused update of the ESC Guidelines for the management of atrial fibrillation: an update of the 2010 ESC Guidelines for the management of atrial fibrillation. Developed with the special contribution of the European Heart Rhythm Association. Eur Heart J. 2012;33(21):2719-47.

26. Heidbuchel H, Verhamme P, Alings M, et al. European Heart Rhythm Association Practical Guide on the use of new oral anticoagulants in patients with non-valvular atrial fibrillation. Europace. 2013;15(5):625-51.

27. Roldan V, Marin F, Fernandez H, et al. Predictive value of the HAS-BLED and ATRIA bleeding scores for the risk of serious bleeding in a "real-world" population with atrial fibrillation receiving anticoagulant therapy. Chest. 2013;143(1):179-84.

28. Qureshi W, Mittal C, Patsias I, et al. Restarting anticoagulation and outcomes after major gastrointestinal bleeding in atrial fibrillation. Am J Cardiol. 2014;113(4):662-8.

29. Weinz C, Schwarz T, Kubitza D, Mueck W, Lang D. Metabolism and excretion of rivaroxaban, an oral, direct factor Xa inhibitor, in rats, dogs, and humans. Drug Metab Dispos. 2009;37(5):1056-64.

30. Frost C, Wang J, Nepal S, et al. Apixaban, an oral, direct factor Xa inhibitor: single dose safety, pharmacokinetics, pharmacodynamics and food effect in healthy subjects. Br J Clin Pharmacol. 2013;75(2):476-87.

31. Ogata K, Mendell-Harary J, Tachibana M, et al. Clinical safety, tolerability, pharmacokinetics, and pharmacodynamics of the novel factor Xa inhibitor edoxaban in healthy volunteers. J Clin Pharmacol. 2010;50(7):743-53.

32. Stangier J, Rathgen K, Stahle H, Gansser D, Roth W. The pharmacokinetics, pharmacodynamics and tolerability of dabigatran etexilate, a new oral direct thrombin inhibitor, in healthy male subjects. Br J Clin Pharmacol. 2007;64(3):292-303.

33. Hartter S, Koenen-Bergmann M, Sharma A, et al. Decrease in the oral bioavailability of dabigatran etexilate after co-medication with rifampicin. Br J Clin Pharmacol. 2012;74(3):490-500.

34. Mendell J, Zahir H, Matsushima N, et al. Drug-drug interaction studies of cardiovascular drugs involving P-glycoprotein, an efflux transporter, on the pharmacokinetics of edoxaban, an oral factor Xa inhibitor. Am J Cardiovasc Drugs. 2013;13(5):331-42.

35. Mueck W, Kubitza D, Becka M. Co-administration of rivaroxaban with drugs that share its elimination pathways: pharmacokinetic effects in healthy subjects. Br J Clin Pharmacol. 2013;76(3):455-66.

36. Mikkaichi T, Yoshigae Y, Masumoto $\mathrm{H}$, et al. Edoxaban transport via P-glycoprotein is a key factor for the drug's disposition. Drug Metab Dispos. 2014;42(4):520-8.

37. Blech S, Ebner T, Ludwig-Schwellinger E, Stangier J, Roth W. The metabolism and disposition of the oral direct thrombin inhibitor, dabigatran, in humans. Drug Metab Dispos. 2008;36(2):386-99.

38. Wang L, Zhang D, Raghavan $\mathrm{N}$, et al. In vitro assessment of metabolic drug-drug interaction potential of apixaban through cytochrome $\mathrm{P} 450$ phenotyping, inhibition, and induction studies. Drug Metab Dispos. 2010;38(3):448-58.

39. Bathala MS, Masumoto H, Oguma T, He L, Lowrie C, Mendell J. Pharmacokinetics, biotransformation, and mass balance of edoxaban, a selective, direct factor Xa inhibitor, in humans. Drug Metab Dispos. 2012;40(12):2250-5.

40. Connolly SJ, Ezekowitz MD, Yusuf S, et al. Dabigatran versus warfarin in patients with atrial fibrillation. $\mathrm{N}$ Engl $\mathrm{J}$ Med. 2009;361(12):1139-51.

41. Patel MR, Mahaffey KW, Garg J, et al. Rivaroxaban versus warfarin in nonvalvular atrial fibrillation. $\mathrm{N}$ Engl $\mathrm{J}$ Med. 2011;365(10):883-91. 
42. Granger CB, Alexander JH, McMurray JJ, et al. Apixaban versus warfarin in patients with atrial fibrillation. N Engl J Med. 2011;365(11):981-92.

43. Giugliano RP, Ruff CT, Braunwald E, et al. Edoxaban versus warfarin in patients with atrial fibrillation. N Engl J Med. 2013;369(22):2093-104.

44. Mendell J, Tachibana M, Shi M, Kunitada S. Effects of food on the pharmacokinetics of edoxaban, an oral direct factor Xa inhibitor, in healthy volunteers. J Clin Pharmacol. 2011;51(5): 687-94.

45. Mendell J, Chen S, He L, Desai M, Parasrampuria DA. The effect of rifampin on the pharmacokinetics (PK) and pharmacodynamics (PD) of edoxaban in healthy subjects. J Thromb Haemost. 2014;12(Suppl):Abstract COA26.

46. Dlott JS, George RA, Huang X, et al. National assessment of warfarin anticoagulation therapy for stroke prevention in atrial fibrillation. Circulation. 2014;129(13):1407-14.

47. Mahaffey KW, Stevens SR, White HD, et al. Ischaemic cardiac outcomes in patients with atrial fibrillation treated with vitamin $\mathrm{K}$ antagonism or factor Xa inhibition: results from the ROCKET AF trial. Eur Heart J. 2014;35(4):233-41.

48. Connolly SJ, Ezekowitz MD, Yusuf S, Reilly PA, Wallentin L. Randomized evaluation of long-term anticoagulation therapy I. Newly identified events in the RE-LY trial. N Engl J Med. 2010;363(19):1875-6.

49. Hart RG, Tonarelli SB, Pearce LA. Avoiding central nervous system bleeding during antithrombotic therapy: recent data and ideas. Stroke. 2005;36(7):1588-93.

50. Go AS, Hylek EM, Chang Y, et al. Anticoagulation therapy for stroke prevention in atrial fibrillation: how well do randomized trials translate into clinical practice? JAMA. 2003;290(20): 2685-92.

51. Hylek EM, Held C, Alexander JH, et al. Major bleeding in patients with atrial fibrillation receiving apixaban or warfarin: the ARISTOTLE Trial (Apixaban for Reduction in Stroke and Other Thromboembolic Events in Atrial Fibrillation): predictors, characteristics, and clinical outcomes. J Am Coll Cardiol. 2014;63(20):2141-7.

52. Hart RG, Diener HC, Yang S, et al. Intracranial hemorrhage in atrial fibrillation patients during anticoagulation with warfarin or dabigatran: the RE-LY trial. Stroke. 2012;43(6):1511-7.

53. Giugliano RP, Ruff CT, Rost NS, et al. Cerebrovascular events in 21105 patients with atrial fibrillation randomized to edoxaban versus warfarin: effective anticoagulation with factor Xa next generation in atrial fibrillation-thrombolysis in myocardial infarction 48. Stroke. 2014;45(8):2372-8.

54. Kasmeridis C, Apostolakis S, Ehlers L, Rasmussen LH, Boriani G, Lip GY. Cost effectiveness of treatments for stroke prevention in atrial fibrillation: focus on the novel oral anticoagulants. Pharmacoeconomics. 2013;31(11):971-80.

55. Pradax (Dabigatran Etexilate) gains approval in Canada for stroke prevention in atrial fibrillation. Medical News Today. 2010. Available at: http://www.medicalnewstoday.com/releases/ 205933.php.

56. European Medicines Agency: Pradaxa (dabigatran etexilate) summary of product characteristics. Available at: http://www. ema.europa.eu/ema/index.jsp?curl=pages/medicines/human/ medicines/000829/human_med_000981.jsp\&mid=WC0b01ac 058001d125. Accessed 11 July 2014. (10/24/2014).

57. Southworth MR, Reichman ME, Unger EF. Dabigatran and postmarketing reports of bleeding. $\mathrm{N}$ Engl $\mathrm{J}$ Med. 2013;368(14):1272-4.

58. Hernandez I, Baik SH, Pinera A, Zhang Y. Risk of bleeding with dabigatran in atrial fibrillation. JAMA Intern Med. 2015; 175(1):18-24. doi:10.1001/jamainternmed.2014.5398.
59. Hohnloser SH, Shestakovska O, Eikelboom J, et al. The effects of apixaban on hospitalizations in patients with different types of atrial fibrillation: insights from the AVERROES trial. Eur Heart J. 2013;34(35):2752-9.

60. Dans AL, Connolly SJ, Wallentin L, et al. Concomitant use of antiplatelet therapy with dabigatran or warfarin in the Randomized Evaluation of Long-Term Anticoagulation Therapy (RE-LY) trial. Circulation. 2013;127(5):634-40.

61. Alexander JH, Lopes RD, Thomas L, et al. Apixaban vs. warfarin with concomitant aspirin in patients with atrial fibrillation: insights from the ARISTOTLE trial. Eur Heart J. 2014;35(4):224-32.

62. Xu H, Ruff CT, Giugliano RP, et al. Concomitant use of antiplatelet therapy with edoxaban or warfarin in patitents with atrial fibrillation in the ENGAGE AF-TIMI 48 Trial. Circulation. 2014;130:A19119.

63. Piccini JP, Stevens SR, Lokhnygina Y, et al. Outcomes after cardioversion and atrial fibrillation ablation in patients treated with rivaroxaban and warfarin in the ROCKET AF trial. J Am Coll Cardiol. 2013;61(19):1998-2006.

64. Cappato R, Ezekowitz MD, Klein AL, et al. Rivaroxaban vs. vitamin $\mathrm{K}$ antagonists for cardioversion in atrial fibrillation. Eur Heart J. 2014;35(47):3346-55.

65. Flaker G, Lopes RD, Al-Khatib SM, et al. Efficacy and safety of apixaban in patients after cardioversion for atrial fibrillation: insights from the ARISTOTLE Trial (Apixaban for Reduction in Stroke and Other Thromboembolic Events in Atrial Fibrillation). J Am Coll Cardiol. 2014;63(11):1082-7.

66. Nagarakanti R, Ezekowitz MD, Oldgren J, et al. Dabigatran versus warfarin in patients with atrial fibrillation: an analysis of patients undergoing cardioversion. Circulation. 2011;123(2):131-6.

67. Sardar P, Nairooz R, Chatterjee S, Wetterslev J, Ghosh J, Aronow WS. Meta-analysis of risk of stroke or transient ischemic attack with dabigatran for atrial fibrillation ablation. Am J Cardiol. 2014;113(7):1173-7.

68. Bassiouny M, Saliba W, Rickard J, et al. Use of dabigatran for periprocedural anticoagulation in patients undergoing catheter ablation for atrial fibrillation. Circ Arrhythm Electrophysiol. 2013;6(3):460-6.

69. McMurray JJ, Ezekowitz JA, Lewis BS, et al. Left ventricular systolic dysfunction, heart failure, and the risk of stroke and systemic embolism in patients with atrial fibrillation: insights from the ARISTOTLE trial. Circ Heart Fail. 2013;6(3):451-60.

70. Diener HC, Connolly SJ, Ezekowitz MD, et al. Dabigatran compared with warfarin in patients with atrial fibrillation and previous transient ischaemic attack or stroke: a subgroup analysis of the RE-LY trial. Lancet Neurol. 2010;9(12):1157-63.

71. van Diepen S, Hellkamp AS, Patel MR, et al. Efficacy and safety of rivaroxaban in patients with heart failure and nonvalvular atrial fibrillation: insights from ROCKET AF. Circ Heart Fail. 2013;6(4):740-7.

72. Magnani G, Giugliano RP, Ruff CT, et al. Efficay and safety of edoxaban compared with warfarin in patients with atrial fibrillation and heart failure: insights from ENGAGE-AF TIMI 48. Circulation. 2014;130:A12680.

73. Deitelzweig S. Care transitions in anticoagulation management for patients with atrial fibrillation: an emphasis on safety. Ochsner J. 2013;13(3):419-27.

74. Patel MR, Hellkamp AS, Lokhnygina Y, et al. Outcomes of discontinuing rivaroxaban compared with warfarin in patients with nonvalvular atrial fibrillation: analysis from the ROCKET AF trial (Rivaroxaban Once-Daily, Oral, Direct Factor Xa Inhibition Compared With Vitamin K Antagonism for Prevention of Stroke and Embolism Trial in Atrial Fibrillation). J Am Coll Cardiol. 2013;61(6):651-8. 
75. Douketis JD, Spyropoulos AC, Spencer FA, et al. Perioperative management of antithrombotic therapy: Antithrombotic Therapy and Prevention of Thrombosis, 9th ed: American College of Chest Physicians Evidence-Based Clinical Practice Guidelines. Chest. 2012;141(2 Suppl):e326S-50S.

76. Ageno W, Gallus AS, Wittkowsky A, et al. Oral anticoagulant therapy: Antithrombotic Therapy and Prevention of Thrombosis, 9th ed: American College of Chest Physicians Evidence-Based Clinical Practice Guidelines. Chest. 2012;141(2 Suppl):e44S88S.

77. Eerenberg ES, Kamphuisen PW, Sijpkens MK, Meijers JC, Buller HR, Levi M. Reversal of rivaroxaban and dabigatran by prothrombin complex concentrate: a randomized, placebo-controlled, crossover study in healthy subjects. Circulation. 2011;124(14):1573-9.

78. Marlu R, Hodaj E, Paris A, Albaladejo P, Cracowski JL, Pernod G. Effect of non-specific reversal agents on anticoagulant activity of dabigatran and rivaroxaban: a randomised crossover ex vivo study in healthy volunteers. Thromb Haemost. 2012;108(2):217-24.

79. Brown K, Wickremasingha P, Parasrampuria D, Kochan J, Dishy V, Shi M. The impact of prothrombin complex concentrate on the anticoagulatory effects of edoxaban. J Am Coll Cardiol. 2014. doi:10.1016/S0735-1097(14)62098-2.

80. Zahir H, Matsushima N, Halim AB, et al. Edoxaban administration following enoxaparin: a pharmacodynamic, pharmacokinetic, and tolerability assessment in human subjects. Thromb Haemost. 2012;108(1):166-75.

81. Fukuda T, Honda Y, Kamisato C, Morishima Y, Shibano T. Reversal of anticoagulant effects of edoxaban, an oral, direct factor Xa inhibitor, with haemostatic agents. Thromb Haemost. 2012;107(2):253-9.

82. Halim AB, Samama MM, Mendell J. Ex vivo reversal of the anticoagulant effects of edoxaban. Thromb Res. 2014;134(4): 909-13.

83. FEIBA NF (Anti-Inhibitor Coagulant Complex), Nanofiltered and Vapor Heated. Package insert. Westlake Village: Baxter Healthcare Corporation; 2011.

84. NovoSeven ${ }^{\circledR}$ RT Coagulation Factor VIIa (Recombinant). Prescribing information. Plainsboro: Novo Nordisk Inc; 2014.

85. Laulicht B, Bakhru S, Lee C, et al. Small molecule antidote for anticoagulants. Circulation. 2012;126(Abstract 11395).

86. Bakhru S, Laulicht B, Jiang X, et al. A synthetic small molecule antidote for anticoagulants. Eur Heart J. 2013;34(Abstract Supplement):88-9(Abstract 1078).

87. Crowther M, Kitt M, McClure M, et al. Randomized, doubleblind, placebo-controlled single ascending dose pharmacokinetic and pharmacodynamic study of PRT064445, a universal antidote for factor Xa inhibitors. Arterioscler Thromb Vasc Biol. 2013;33:Abstract 10.

88. Boehringer Ingelheim's Investigational Antidode for Pradaxa ${ }^{\circledR}$ (dabigatran etexilate mesylate) Receives FDA Breakthrough Therapy Designation [press release]. Ridgefield: Boehringer Ingelheim; 2014. http://us.boehringer-ingelheim.com/news_ events/press_releases/press_release_archive/2014/06-26-14-boeh ringer-ingelheim-investigational-antidote-pradaxa-dabigatranetexilate-mesylate-fda-breakthrough-therapy-designation.html. Accessed 6 Oct 2014.

89. Chang DN, Dager WE, Chin AI. Removal of dabigatran by hemodialysis. Am J Kidney Dis. 2013;61(3):487-9.

90. Kubitza D, Becka M, Mueck W, et al. Effects of renal impairment on the pharmacokinetics, pharmacodynamics and safety of rivaroxaban, an oral, direct Factor Xa inhibitor. $\mathrm{Br} \mathrm{J}$ Clin Pharmacol. 2010;70(5):703-12.

91. Stangier J, Rathgen K, Stahle H, Mazur D. Influence of renal impairment on the pharmacokinetics and pharmacodynamics of oral dabigatran etexilate: an open-label, parallel-group, singlecentre study. Clin Pharmacokinet. 2010;49(4):259-68.

92. Salazar DE, Mendell J, Kastrissios H, et al. Modelling and simulation of edoxaban exposure and response relationships in patients with atrial fibrillation. Thromb Haemost. 2012;107(5): 925-36.

93. Hijazi Z, Hohnloser SH, Oldgren J, et al. Efficacy and safety of dabigatran compared with warfarin in relation to baseline renal function in patients with atrial fibrillation: a RE-LY (Randomized Evaluation of Long-term Anticoagulation Therapy) trial analysis. Circulation. 2014;129(9):961-70.

94. Hohnloser SH, Hijazi Z, Thomas L, et al. Efficacy of apixaban when compared with warfarin in relation to renal function in patients with atrial fibrillation: insights from the ARISTOTLE trial. Eur Heart J. 2012;33(22):2821-30.

95. Fox KA, Piccini JP, Wojdyla D, et al. Prevention of stroke and systemic embolism with rivaroxaban compared with warfarin in patients with non-valvular atrial fibrillation and moderate renal impairment. Eur Heart J. 2011;32(19):2387-94.

96. You JJ, Singer DE, Howard PA, et al. Antithrombotic therapy for atrial fibrillation: Antithrombotic Therapy and Prevention of Thrombosis, 9th ed: American College of Chest Physicians Evidence-Based Clinical Practice Guidelines. Chest. 2012;141(2 Suppl):e531S-75S.

97. Marinigh R, Lip GY, Fiotti N, Giansante C, Lane DA. Age as a risk factor for stroke in atrial fibrillation patients: implications for thromboprophylaxis. J Am Coll Cardiol. 2010;56(11): 827-37.

98. van Walraven C, Hart RG, Connolly S, et al. Effect of age on stroke prevention therapy in patients with atrial fibrillation: the atrial fibrillation investigators. Stroke. 2009;40(4):1410-6.

99. Fang MC, Go AS, Hylek EM, et al. Age and the risk of warfarinassociated hemorrhage: the anticoagulation and risk factors in atrial fibrillation study. J Am Geriatr Soc. 2006;54(8):1231-6.

100. Eikelboom JW, Wallentin L, Connolly SJ, et al. Risk of bleeding with 2 doses of dabigatran compared with warfarin in older and younger patients with atrial fibrillation: an analysis of the randomized evaluation of long-term anticoagulant therapy (RE-LY) trial. Circulation. 2011;123(21):2363-72.

101. Kato ET, Giugliano RP, Ruff CT, et al. Efficacy and safety of edoxaban for management of elderly patients with atrial fibrillation: ENGAGE AF-TIMI 48. Circulation. 2014;130:A16612. 